\title{
Application of Medical Ethics in the Medical Simulation Education
}

\author{
Manli Wang ${ }^{1, ~ a ~}$, Bin Zhao ${ }^{2,3, b}$ and Xiuling Sun ${ }^{4, c^{*}}$ \\ ${ }^{1}$ College of Pharmacy, Beihua University, 3999 East Binjiang Road, Fengman District, Jilin, Jilin, \\ 132013, People's Republic of China \\ ${ }^{2}$ Affiliated hospital of Beihua University, 12 Jiefang road, Chuanying District, Jilin, Jilin, 132013, \\ People's Republic of China \\ ${ }^{3}$ General Hospital of CNPC in Jilin, 52 Zunyi Road, Longtan District, Jilin, Jilin, 132013, People's \\ Republic of China
}

${ }^{4}$ Basic Medical College, Beihua University, 3999 East Binjiang Road, Fengman District, Jilin, Jilin, 132013, People's Republic of China

abhwangml@163.com, b54218098@qq.com, 'sunxiuling2005@163.com

*Corresponding Author: Xiuling Sun, Email: sunxiuling2005@163.com

Keywords: Medical ethics; Medical simulation education; Medical education; Clinical practice.

Abstract. Medical ethics is from the special relationship between doctors and patients in medical work. It is the subject of solving the medical ethics issues and phenomena in the process of medical practice and development using the general ethics. It is both part of the medicine and part of ethics. In this paper, through the analysis on the current situations of medical education in our country, the application of medical ethics in medical simulation education is discussed to understand the relationship between medical ethics and medical simulation education for the integration of medical ethics into the medical simulation education.

\section{Introduction}

"Global medical education most basic requirements (GMER)" was official published in 2002. It covers seven big field, including career value, and attitude, and behavior and ethics, medical science based knowledge, clinical skills, exchange skills, groups health and health system, information management, criticism sex thinking and research. And it reflects that the medical mode has changed, health implementation was internationalization, medical education reform and development of trend with the close combination of humanities education and medical science education, has became the basic standard of training medical students and evaluation medical education of medical school[1].

Medical simulation education[2] is a education way which "simulation ' real "' for teaching, it advocates to carry out teaching and assessment in a way that as close to real clinical environment and more meet medical ethics. It creates out simulation patients and simulation clinical scene, using variety local function model, and computer interactive model and virtual technology, simulation system. Through construction clinical skills simulation laboratory, and medical simulation Center, and simulation Hospital, it is the bridge between medical theory and clinical practice. It uses more scientific and humanistic teaching and examination means to cultivate medical students' clinical thinking, and comprehensively improve the students' ability for clinical diagnosis and the clinical skills, so as to effectively reduce medical errors and disputes in the clinical practice.

Medical ethics is a science to study moral issues in the medical field using the theory and approaches of ethics, in which the general principles of ethics are specifically applied in the medical practice.[3] Medical Ethics centers on life and focuses on morality to reflect social requirements for medicine, and ideas of patient first and life first.[4] With the development of medical and health services, medical ethics has developed into a social undertaking taking the doctor-patient relationship as the core. 


\section{Current Situations of Medical Education}

With the development of modern medicine, the medical education has been developed to a new stage in China, towards the holistic and integrated direction. However, medical ethical problems are still problematic. The main features are as follows.

Contradictory practices and ethics requirements. It is well known that practice makes perfect and medicine always emphasizes practice. Only does he or she personally deals with numerous cases in the medical practice, a doctor can grow up to a real doctor. However, the teaching mode taking patients as the practical object obviously violates the ethical requirements. Although the teaching mode taking patients as the practical object can help the students learn and gain experience for the future work, the patients have to often receive repeated examinations when they suffer the pain of diseases and simultaneously "are practiced", which may give the patient great inconvenience and pain.

Problems in the teaching of clinical medicine. For a long time, the teaching of medical professional knowledge is always emphasized, but the learning of practical ability is ignored, and the training of theoretical knowledge and practical skills is disjointed in China. However, although the profession of doctors emphasizes the practical operation, a method and approach for the unified comprehensive clinical skills practice has been not formed yet and clinicians try to make the patient discharged away from the pain and suffering as soon as possible so that many medical schools can not provide good opportunities for students to practice. In addition, the learning method to assess students' clinical practical skills by examine or treat patients can not be cooperated by the patients or their relatives, leading to the shortage of resources in the clinical education.

\section{Requirements and Approaches of Medical Ethics teaching}

Requirements for medical Ethics teaching. The research and service object of medicine is human being so that it is necessary to pay more attention to patient's demands. Whether beneficial to the health of patients or not, doctors only have the fight to tell their patients about the therapeutic regimen, but no right to choose it on behalf of patients.[5] Patients have the right s to choose a therapeutic regimen for themselve, and whether the choice is correct or not, doctors only have the right to admonish them, but no right to change the therapeutic regimen chosen by patients, in which individual rights of patients can be greatly respected and reflected.[6] Whenever, morality is the only criterion for judging whether a person is noble. The professional nature of doctors is special and the moral requirements for it is much strict than those of other professions. With the development of economic times, people's value orientation is gradually diversified, so that some medical staff has lost the awareness on professional ethics to utilize the patient's pain to make a fortune, such as receiving a red envelope, randomly prescribing, showing utilitarianism and treating patients with indifference, exacerbating the conflict between doctors and patients. Medical ethics education also requires that doctors should have good communication skills, be affable when they face with patients, ask about the physical condition of patients in detail, listen carefully to the patient's problem, answer the patient's questions in detail, and well understand the patients with a bad attitude. It is believed that a good communication ability is one of the basic requirements for a doctor to win the respect and trust of patients and improve the relationship between doctors and patients.

Approaches of Medical Ethics teaching. The systemic education of medical ethics should be strengthened and the cultivation of humanistic quality should be emphasized. The impact of education in schools is great and schools should focus on the education of morality and medical ethics in students. For in-service doctors, the medical ethics education should be combined with the actual working situation in hospitals, and from humanistic spirit and the law, and considering the examples around them, doctors receive the medical ethics education to improve their professional quality and professional ethics, and culture the working spirit of loving their work and dedication to their work.[7] With the progress of society, medicine began to emphasize the respect for human beings. Now medicine is not only a natural science or a social science. The harmony of doctor-patient relationship is inseparable from the human quality of medical staff. By improving the humanistic quality of medical 
personnel, a good doctor-patient relationship and good treatment atmosphere can be created. Respect for patients and care for patients please.

\section{Application of Medical Ethics in the Medical Simulation Education}

Medical simulation education is to use simulation technology to simulate patients and clinical scenarios, and is an extension of simulation teaching application in medicine or clinical. Medical simulation education is a reflection of medical ethics throughout medical education.

To increase contact of students with patients and develop a good habit to care for patients. Medical simulation education can increase the contact between students and patients, and allow students to accumulate experience in contact with the patient, strengthen the communication capacity of students with patients and learn how to deal with the doctor-patient relationship.[8] The doctor-patient relationship has become a big issue in the medical treatment and a good communication between doctors and patients has become a thing that can not wait to do. Having good communication skills has become one of the indispensable conditions for doctors. By strengthening clinical simulation to increase clinical practice opportunities for students, it is possible to cultivate students and doctors and patients' communication ability, understand their communication skills with patients, well apply the knowledge of medical ethics in the practice, and train the students to have habits to care for and love patient patient's in their practice for the cultivation of their good medical morality.

To avoid medical ethics problems in the medical simulation education and improve the doctor-patient relationship. The profession of doctors is rather sensitive. The privacy of patients may be involved in the process of treatment. For example, in gynecology or urology, the patients need to expose their private parts during the process of treatment, and thereby will inevitably become sensitive and shame due to the exposure, especially in those with too strong self-esteem, so that it is easy to cause medical disputes between the medical staff and the patients even in the slightest mistake. In the process of medical simulation education, the students can be trained not only in their problem-solving ability and medical morality, but also in the habit to protect their patients' privacy; the students can develop a good psychological quality and teamwork spirits; the students can understand diseases more profoundly and more vividly, and be cultivated in their cognition and solving abilities for medical ethics issues to improve the doctor-patient relationship[9].

The combination of medical simulation education with medical ethics can accelerate the process for the students to understand the knowledge that has learned, help reduce the conflicts between doctors and patients, be in line with the idea of the close integration of humanistic quality into scientific education in the medical education, and be beneficial to the professional training of clinical doctors and the overall development of quality education, which should be a good approach for the development of medical education.

\section{Acknowledgments}

This work was supported by the Young Teacher educational research program of Beihua University (Grant No. 2014038QH).

\section{References}

[1] Z. Guo, N. Cheng, B.Wang, Implementing global minimum essential requirements in medical education, based on simulated hospital for clinical teaching, Chinese Journal of Evidence-Based Medicine, 9 (2009) 625-629.

[2] Y. Huang, Application of medical simulation technology in medical education, Journal of Modern medicine and health, 23 (2007) 790-791.

[3] C. Huang. Application of creative education in the teaching process of medical ethics course. Journal of Chongqing University of Posts and Telecommunications (Social Science Edition), 3 (2010) 448-450. 
[4] R. Jagsi, and L. Lehmann, The ethics of medical education. British Medicine Journal, 8 (2012) 55 $-57$.

[5] Z. Duan, and R. Wang, Ethical thought of "reverence for life" and its significances in medical education, Acta Universitatis Medicinalis Nanjing (Social Science Edition), 9 (2010) 204-206.

[6] C. Layat Burn, SA. Hurst, M. Ummel, B. Cerutti, and A. Baroffio, Telling the truth: medical students' progress with an ethical skill, Med Teach. 36 (2014) 251-259.

[7] MA. Gisondi, R. Smith-Coggins, PM. Harter, RC. Soltysik, and PR Yarnold, Assessment of resident professionalism using high-fidelity simulation of ethical dilemmas, Acad Emerg Med. 11 (2004) 931-937.

[8] T. Logar, P. Le, JD. Harrison, M.Glass, Teaching corner: "first do no harm": teaching global health ethics to medical trainees through experiential learning, J Bioeth Inq. 12 (2015) 69-78.

[9] M. Botezatu, H. Hult, and UG. Fors, Virtual patient simulation: what do students make of it? A focus group study, BMC Med Educ. 10 (2010) 91. 